\title{
Thymoquinone Augments Cyclophosphamide-Mediated Inhibition of Cell Proliferation in Breast Cancer Cells
}

\author{
Arif Khan*, Yousef H Aldebasi, Sultan A Alsuhaibani, Masood A Khan
}

\begin{abstract}
Objective: Cancer chemotherapy at the recommended doses is largely associated with toxicity, and also it is not effective enough to reduce the advancement of the disease at lower doses. Thymoquinone (TQ) is an active compound derived from black seeds (Nigella sativa) which exhibits anticancer activities. The aim of the present study was to investigate the synergistic effect of TQ alone and in combination with cyclophosphamide (cyclo), and to unravel the role of TQ in fatty acid synthase (FASN) mediated molecular signaling in Her2 + and Her2- breast cancer cell lines. Methods: The effect of TQ on the growth of Her2+ SKBR-3 and Her2- MDA-231 breast cancer lines were evaluated as percent cell viability by cytotoxicity-based MTT assay. The analysis of cell cycle arrest was done through flowcytometry followed by Western blot and RT-PCR to detect signaling events in the cells. Results: The data showed that TQ-cyclo $(0.5 \mathrm{mM}-10 \mu \mathrm{M})$ combination significantly inhibited the proliferation through the $5.49 \%$ and $57.72 \%$ accumulation of cells in sub-G1 and G1 respectively as $12 \%$ cells were shifted from G2/M phase in Her2+ breast cancer cells. Similarly, TQ-cyclo $(0.5 \mathrm{mM}-20 \mu \mathrm{M})$ combination exhibited that the $16.6 \%$ cells were arrested in Sub-G1 and only $3.54 \%$ cells were remained in G2/M phase as it was $22.89 \%$ in DMSO control in Her-2- breast cancers cells. Though TQ alone or in combination with cyclo alleviated the PI3K/Akt signaling by downregulating the phosphorylation of Akt and upregulating the PTEN, no changes was observed in FASN and Her-2 as well in both type of cells. The significant decreased expression of cyclin D1 was found in TQ-cyclo combinations. Conclusion: The current findings suggested that TQ can alter the cell cycle progression and induce cell death independent of FASN mediated signaling. In terms of clinical perspective, the present study clearly showed that TQ can broadly augment the effect of cyclo in breast cancer cases irrespective of Her-2+ or Her-.
\end{abstract}

Keywords: Thymoquinone (TQ)- FASN- Her2- Cyclophosphamide (Cyclo)

Asian Pac J Cancer Prev, 20 (4), 1153-1160

\section{Introduction}

Anticancer drugs are usually afflicted with toxic manifestations at required amount of doses to control the process of carcinogenesis at various stages. In recent years, the potential of active dietary constituents to fight against the cancer has engrossed widespread attention. Thymoquinone (TQ) is the main bioactive constituent of black seeds (Nigella sativa) which has been shown to possess many biological activities relevant to human cancer prevention and treatment. As substantiated from several studies, TQ is a promising anti-cancer therapeutic compound affecting multiple signaling pathways that can control cell division and growth, apoptosis, inflammation, angiogenesis, and metastasis (Reddy et al., 2003; Yi et al., 2008; Arafa et al., 2011; Younus., 2018; Rajput et al., 2013). The therapeutic implications of liposomal TQ to combat fluconazole-resistant Candida albicans in a murine model has been proved earlier (Khan et al., 2015). Combining the active chemotherapeutic reagent at the lowest level of toxicity with agents that target specific molecular mechanism offers a promising strategy for the treatment of cancer and may counteract human cancer cells resistant to the drugs (Norwood et al., 2007; Lei et al., 2012; Williams et al., 2014; Harpole et al., 2015).

Several studies have suggested fatty acid synthase (FASN) as a potential molecular target in the treatment of cancers, especially breast cancer (Rysman et al., 2010; Ventura et al., 2015; Gonzalez-Guerrico et al., 2016). As evident from human studies, FASN is upregulated in infiltrating carcinomas in comparison to non-transformed epithelial tissues adjacent to tumors (Kuhaida et al., 2000; Bhatt et al., 2012; Cai et al., 2014). Moreover, it is eminent that higher level of FASN may regulate oncogenic proteins associated with malignant transformation, suggesting its important role in the progression of cancer. Interestingly, many studies have shown the interplay between FASN and cellular localization of Her-2 oncogene in breast cancer cells. Therefore, substantial interest has been targeted toward identifying natural occurring active

College of Applied Medical Sciences, Qassim University, Buraidah, Al-Qassim, Saudi Arabia. *For Correspondence: arifbiotech@gmail.com 
dietary constituents as inhibitors of this enzyme. The potential of neutraceuticals such as green tea polyphenol epigallocatechin-3-gallate (EGCG) and other flavonoids against breast cancer through downregulating the FASN activity has been suggested by previous studies (Pan et al., 2007; Puig et al., 2008; Khan et al., 2014). We previously reported the correlation of resveratrol-induced inhibition of cell proliferation with the status of FASN and Her2 expression in breast cancer cells. We found that resveratrol constrained the growth of Her2 expressed breast cancer cells by inhibiting FASN in a dose dependent manner. Keeping these views into considerations, the aims of the present study were to analyze the effect of TQ alone or in combination with low dose of cyclophosphamide, and to determine the role of FASN in TQ mediated growth inhibition.

\section{Materials and Methods}

\section{Materials}

Cyclophosphamide Thymoquinone and polyvinylidene fluoride (PVDF) membrane were purchased from Santa Cruz Biotechnology, Inc. (California, USA). Antibodies (Abs) against p185Her2, FASN, Cyclin D1, $\beta$-actin, PEA3, Akt, phospho-Akt (Ser473), p85-PI3K, PTEN, and Rabbit anti mouse horseradish peroxidase or goat anti rabbit horseradish peroxidase-conjugated secondary antibodies were purchased from ABCAM (Cambridge, USA). The polyvinylidene fluoride (PVDF) membrane was obtained from Santa Cruz Biotechnology. The rest of the chemicals were of analytical grade of purity and were procured locally.

\section{Cell culture}

SKBR-3 and MDA-231 breast cancer cells were procured from American Type Culture Collection (ATCC), and sub-cultured in DMEM from Santa Cruz Biotechnology Inc. (California, USA) comprising of $10 \%$ fetal bovine serum (FBS), 1\% L-glutamine, 1\% sodium pyruvate, $50 \mathrm{U} / \mathrm{ml}$ penicillin, and $50 \mathrm{mg} / \mathrm{ml}$ streptomycin from Sigma-Aldrich (Missouri, USA). The culture conditions of the cells were maintained at $37^{\circ} \mathrm{C}$ in a humidified atmosphere of $95 \%$ air and $5 \% \mathrm{CO}_{2}$.

\section{Treatment of cells}

The primary screening was performed to evaluate the effects of cyclophosphamide on the inhibition of cell proliferation at different concentrations, including $0.1,0.2,0.5,1.0,2.5,5.010 .0,25.0$, and $50.0 \mathrm{mM}$ by MTT cell proliferation assay. According to the inhibition of cell proliferation, $0.5 \mathrm{mM}$ dose was selected which showed only $15-20 \%$ cell death. The stock solution of TQ (1 mM) was prepared in dimethyl sulphoxide (DMSO) and diluted with complete medium (without antibiotics) to achieve the required concentration used for the treatment of cells (Figure 1a). The cells were exposed to different concentrations of TQ $(0,1,2,5,10,15,20,25,30,35$, $40,45,50,75$ and $100 \mu \mathrm{M}$ ) for $48 \mathrm{~h}$. In the controls, the cells were incubated with the vehicle (DMSO) alone.

\section{Cell cytotoxicity assay}

The cell cytotoxicity assay kit (colorimetric) from abcam was used to assess the cell viability according to manufacturer's instructions. Briefly, 1 X $10^{4}$ cells $(200$ $\mu 1)$ were plated in 96-well microtitre plates in culture medium followed by the treatment of cells with various concentrations of TQ and incubated at $37^{\circ} \mathrm{C}$ in $\mathrm{CO}_{2}$ incubator. Following $48 \mathrm{~h}$ of incubation with TQ alone and TQ in combination with cyclo $(0.5 \mathrm{mM})$, reagent was added, and absorbance of the samples were taken at $570 \mathrm{~nm}$ and $605 \mathrm{~nm}$ on a multiwall plate reader. The ratio of OD570 to OD605 was used to determine the cell viability in each well. The percentage of cell viability was calculated using the following formula:

$$
\% \text { Cell viability }=100 X\left(\mathrm{R}_{\text {sample }}-\mathrm{R}_{\mathrm{o}}\right) /\left(\mathrm{R}_{\text {ctrl }}-\mathrm{R}_{\mathrm{o}}\right)
$$

$\mathrm{R}_{\text {sample }}$ is the absorbance ratio of $\mathrm{OD}_{570} / \mathrm{OD}_{605}$

$\mathrm{R}_{\text {ctrl }}$ is the absorbance ratio of $\mathrm{OD}_{570} / \mathrm{OD}_{605} \mathrm{DMSO}$ control

$\mathrm{R}_{\mathrm{o}}$ is the average background (non-cell control) absorbance ratio of $\mathrm{OD}_{570} / \mathrm{OD}_{605}$

Flow-cytometric analysis of cell cycle

$1 \times 10^{6}$ cells grown in $100-\mathrm{mm}$ culture plates were treated with two selected doses of TQ $(0,10,20 \mathrm{mM})$ for $48 \mathrm{~h}$ after. The treated cells were harvested in phosphate-buffered- saline (PBS) followed by fixation in $70 \%$ ice-cold ethanol. After incubation for $24 \mathrm{~h}$, cells were treated with $50 \mu \mathrm{g} / \mathrm{ml}$ propidium iodide (PI) and $100 \mu \mathrm{g} /$ $\mathrm{ml}$ Ribonuclease A (RNAse A) and incubated at $37^{\circ} \mathrm{C}$ for $30 \mathrm{~min}$. The samples were measured using MACSQuant Analyzer 10 and raw data were acquired and analyzed for flow cytometry using MACSQuantify software version 2.4 (Miltenyi biotec, Germany).

\section{Western-blot analysis}

Western blotting was carried out as described previously (Chou et al., 1984). Briefly, BCA protein assay kit (Thermo Scientific, Rockford, USA) was used to estimate the concentration of protein in cell lysates. Proteins (40 mg) were resolved on 6-12\% sodium dodecyl sulphate (SDS)-polyacrylamide gels and transferred on PVDF membranes in wet protein transfer system. The blots were blocked for 30-40 minutes with 5\% skimmed milk followed by probing with required antibodies at dilutions instructed by the suppliers. The detection of immunoblots through chemiluminescence was done using enhanced chemiluminescence reagents obtained from Millipore (Billerica, USA). Data were presented as the relative density of protein bands normalized to b-actin as membranes were re-probed with it as an internal control. The intensities of the bands were measured using Image Analysis software on an Image Gel Documentation System.

Reverse transcriptase-polymerase chain reaction (RT-PCR) assay

Total RNA was extracted using MagaZorb® Total RNA Mini-Prep Kit (promega) followed by RT-PCR for Her-2 transcript on Bio-Rad C1000 Touch Thermal 
Cycler by using reverse transcription system (Promega) according to the manufacturer's instructions. The primers sequences to amplify Her-2 transcript were 50-GACCCGCTGAACAATACCAC-30 (forward) and 50-TGCCGTCGTCTTCTAGGCCTTCAT-30 (reverse). In each reaction, GAPDH cDNA was amplified as an internal. Reaction mixture was first denatured at $95^{\circ} \mathrm{C}$ for $10 \mathrm{~min}$. PCR conditions were $95^{\circ} \mathrm{C}$ for $1 \mathrm{~min}, 60^{\circ} \mathrm{C}$ for $2 \mathrm{~min}$, and $728^{\circ} \mathrm{C}$ for $2 \mathrm{~min}$ for 30 cycles followed by $72^{\circ} \mathrm{C}$ for $10 \mathrm{~min}$.

\section{Statistical analysis}

Means and standard deviation (SD) were calculated for all treated samples and vehicle controls. The Student's t-test for the paired samples and one way ANOVA Holm-Sidak for different treated sample were used to evaluate the statistical significance of differences between parameters (Sigma Stat 3.5, Systate Software Inc., San Jose, USA).

\section{Results}

As depicted in Figure 1a, it was found that $0.5 \mathrm{mM}$ concentration of cyclo inhibited the proliferation of cells by $\sim 15 \%$ and $10 \%$ in Her2+ and Her2- breast cancer cells, respectively. which was selected for further studies.
$T Q$ amplified the growth inhibition of both Her2+ and Her2- breast cancer cells

The preliminary screening of TQ was executed to assess the effect of various concentrations of TQ on the cellular proliferation and cell viability using the cell cytotoxicity assay kit. As depicted in Figure 1b and 1c, the incessant degenerations in the viability of Her2+ and Her2- cells were measured with increasing doses of TQ $(5-150 \mu \mathrm{M})$. The $\mathrm{IC}_{50}$ value for growth inhibition was obtained at $\sim 34 \mathrm{mM}$ but reduced to 24 and 22.5 $\mathrm{mM}$ in Her2+ and Her2- cells respectively while treated the in combination with $0.5 \mathrm{mM}$ cyclo. Based on these observations, we selected two concentrations of TQ below IC50 of combination i.e. 10 and $20 \mathrm{mM}$ for further mechanistic studies over a $48 \mathrm{~h}$ period with constant dose $(0.5 \mathrm{mM})$ of cyclo.

$T Q$ enlarged the accumulation of cyclo treated cells in G1 and sub-G1 in both Her2+ and Her-breast cancer cells

The treatment of cells with TQ in combination with cyclo exhibited that the cells accumulated in sub-G0 and G1 in dose dependent manner. The marginal shift from G2/M and S phase to sub-G1 and G1 was observed in Her $2+$ cells treated with TQ, while approximately $7 \%$ change from $\mathrm{G} 2 / \mathrm{m}$ to $\mathrm{G} 1$ was observed in the cells treated with cyclo. Remarkably, very significant transformation
A

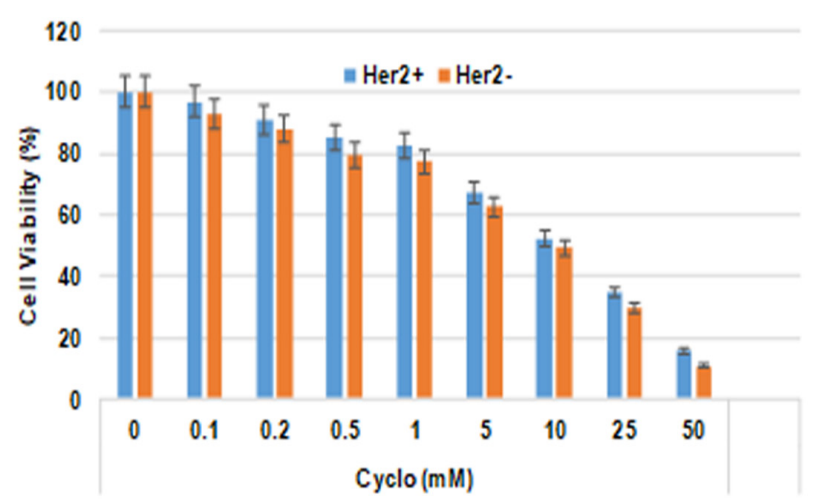

B

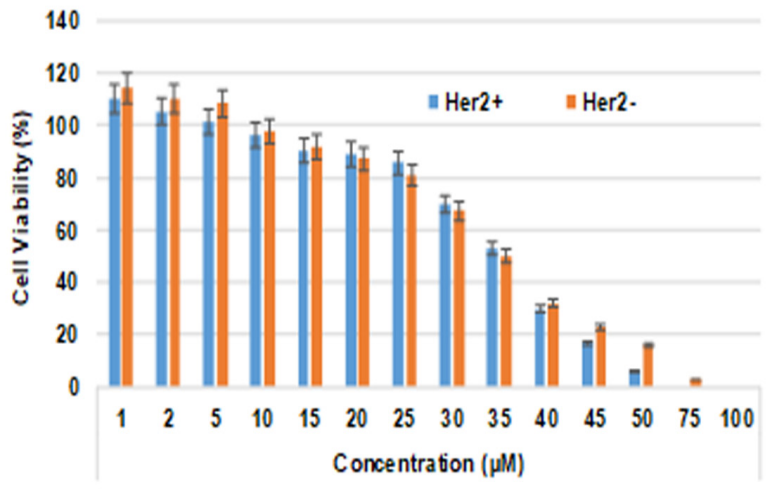

C

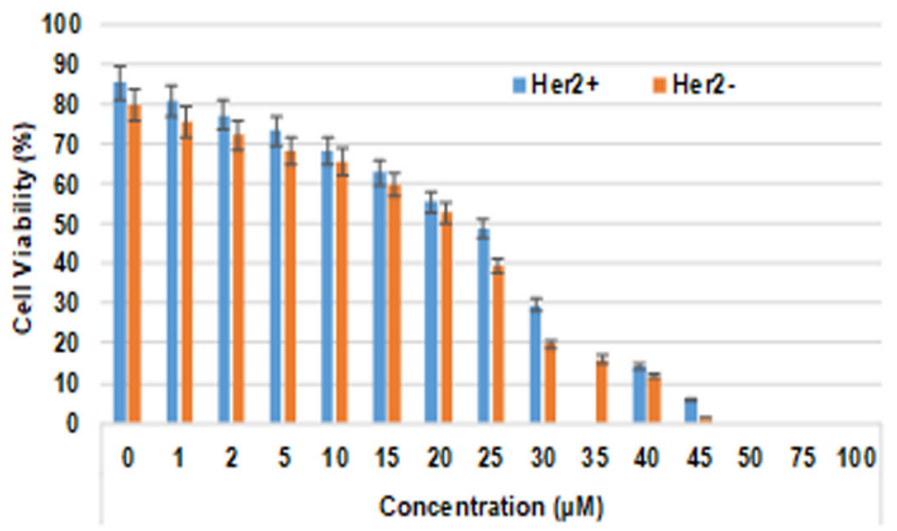

Figure 1. Effect of TQ and Cyclo on Her2+ and Her2- Breast Cancer Cells. (A) Varying concentrations of cyclo (B) Varying concentrations of TQ (C) Varying concentration of TQ in combination with constant concentration of cyclo $(0.5 \mathrm{mM}) .1 \times 10^{4}$ cells $(200 \mu \mathrm{l})$ were treated with different concentrations of TQ $(0,1,2,5,10,15,20,25,30,35,40$, $45,50,75$ and $100 \mu \mathrm{M}$ ) for $48 \mathrm{~h}$. The percentage of cell growth inhibition was measured by cell cytotoxicity assay as described in methods section. Values are represented as the percentage of viable cells; data represent mean percentages of viable cells $\pm \mathrm{SD}$ of three independent experiments. 
A
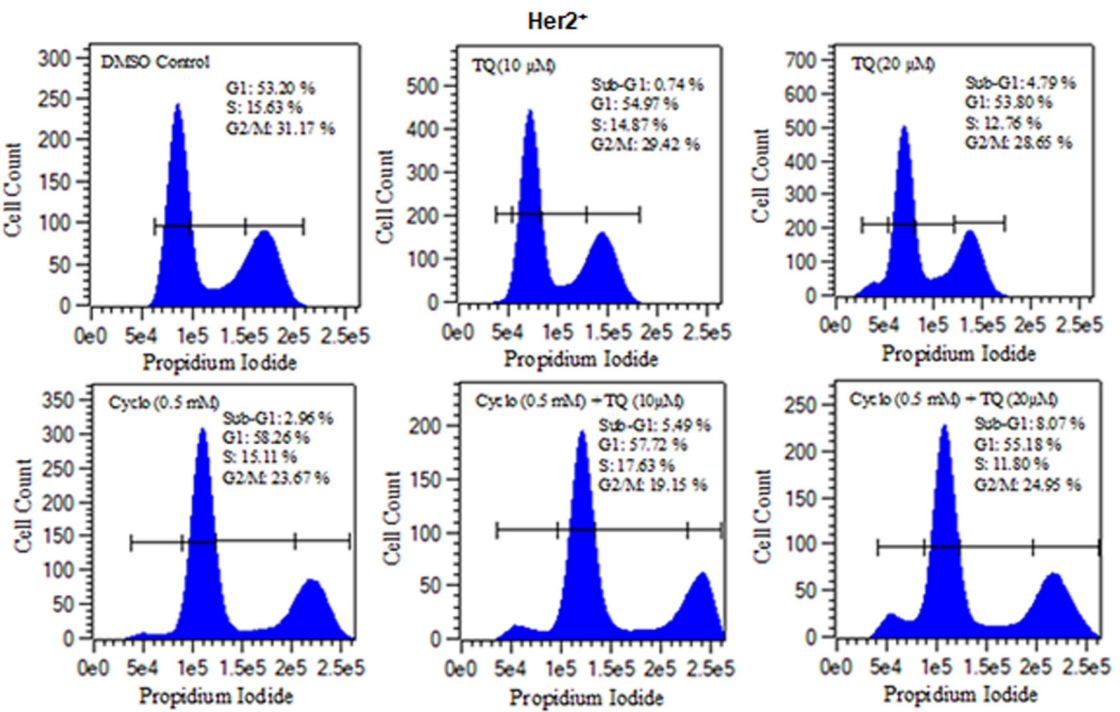

B
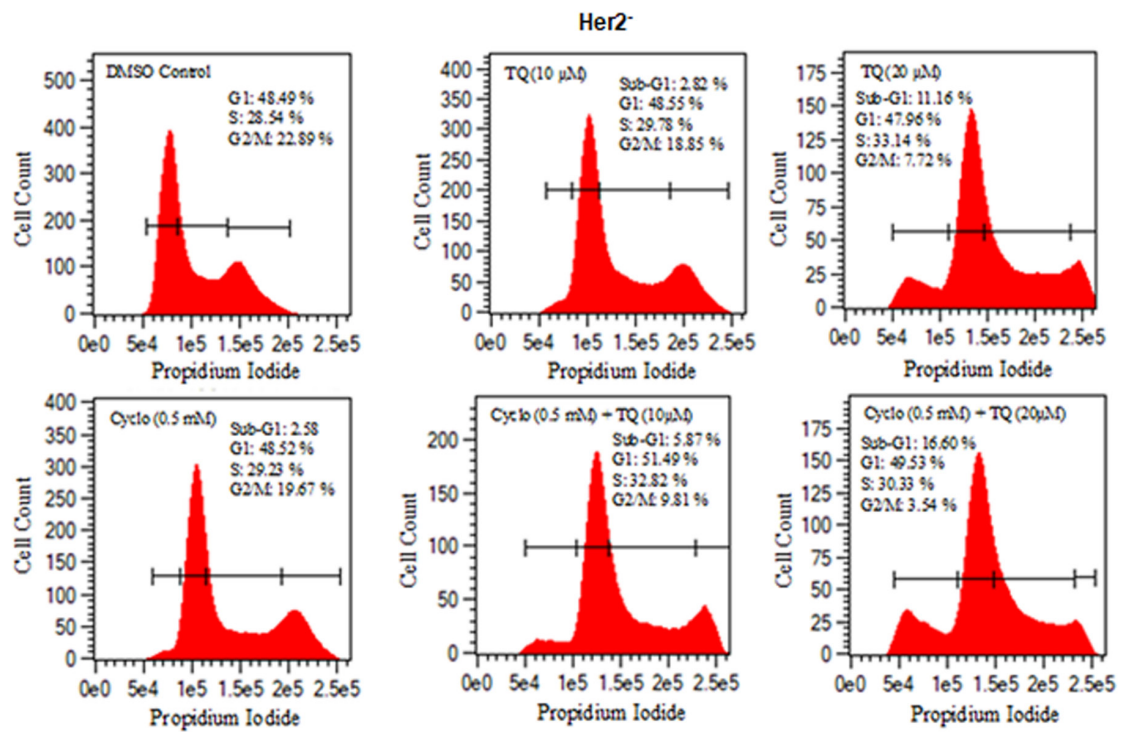

Figure 2. Effect of TQ, Cyclo and TQ-Cyclo Combination on Cell Cycle Progression in (A) HER2+ breast cancer cells (B) Her2- breast cancer cells. 1 x 104 cells $(200 \mu \mathrm{l})$ were treated with TQ $(10,20 \mu \mathrm{M})$ with or without cyclo $(0.5 \mathrm{mM})$ for $48 \mathrm{~h}$, and DNA cell-cycle analysis was performed as described in Section 2 . Vehicle control cells showed no sub-G1 peak, whereas TQ-treated cells contained cells in sub-G1, as determined by flow-cytometry analysis; PI fluorescence intensity was measured as an indicator of cellular DNA content.

was discovered in the cells exposed to TQ in combination with cyclo as $5.49 \%$ cells were arrested in sub-G1 and $57.72 \%$ in G1 as $10 \%$ cells were shifted from G2/M. In the cells treated with TQ $20 \mu \mathrm{M}$ and Cyclo, showed significant shift into sub-G1 $8.07 \%$ from G1 in comparison to control other treated groups (Figure 2a).

In Her2- cells, the accumulation of cells in sub-G1 and G1 were observed dose dependently more significantly in comparison to Her $2+$ cells. It showed that $11.16 \%$ in sub-G1 and $\sim 48 \%$ cells were arrested while the treated with $20 \mu \mathrm{M} \mathrm{TQ}$. However, this swing was more prominent in the cells treated with $20 \mu \mathrm{M}$ TQ and cyffclo as only 3.54 $\%$ cells were remained in $\mathrm{G} 2 / \mathrm{M}$ phase, while $16.6 \%$ cells were recorded in sub-G1 phase (Figure 2b).

$T Q$ induced the inhibition of Akt phosphorylation alters Akt/PI3K/mTOR pathway

PI3K kinase regulates the key molecular pathways crucial for biological processes like cell proliferation and cell motility (Chan et al., 1999). The phosphorylation of Akt at S473 plays a vital role in essential cellular by phosphorylating several downstream substrates. Several studies have shown the association between PI3K/ AKT signaling pathway and TQ-mediated inhibition of different cell types growth (Khan et al., 2017; Su et al., 2016; Dirican et al., 2015). As shown in Figure 3a and b, simultaneous downregulation and upregulation of $\mathrm{pAkt}$ and PTEN were noticed in dose dependently manner, and showed most effective with concomitant exposure of TQ $(20 \mathrm{mM})$ and cyclo $(\mathrm{p}<0.001)$ against vehicle control and cyclo alone as well.

To characterize the possible effect of TQ on Her-2 over-expressed breast cancer cells, we determined the changes in the expression of FASN and Her2/neu in Her2+ and Her2- breast cancer cells. Interestingly, we observed no changes in FASN and Her2 expression in comparison to vehicle in any of the treated groups. These data ruled out the inhibition of cell proliferation by TQ either alone or in 
A

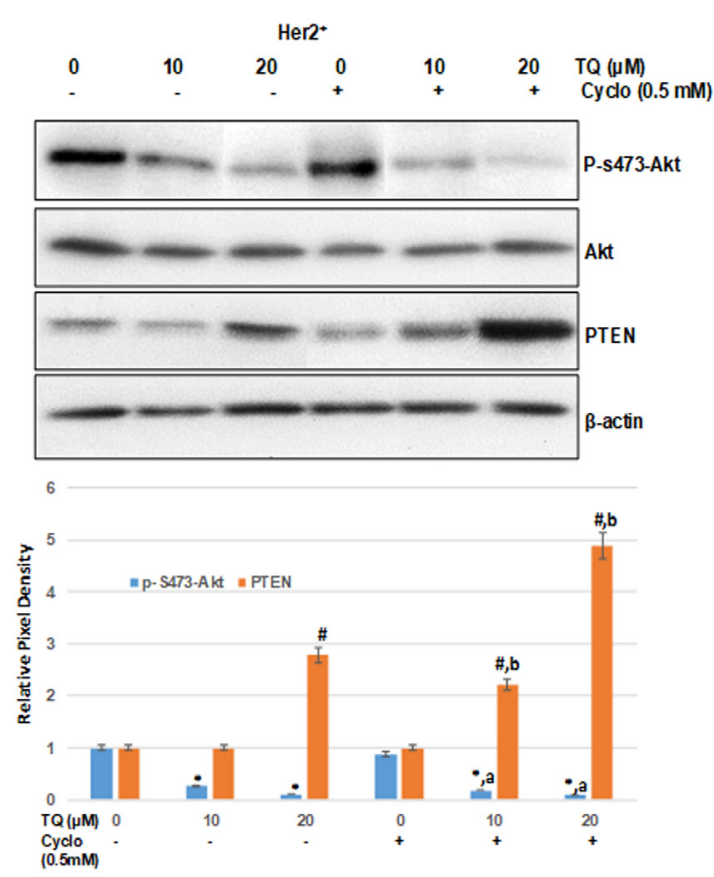

B

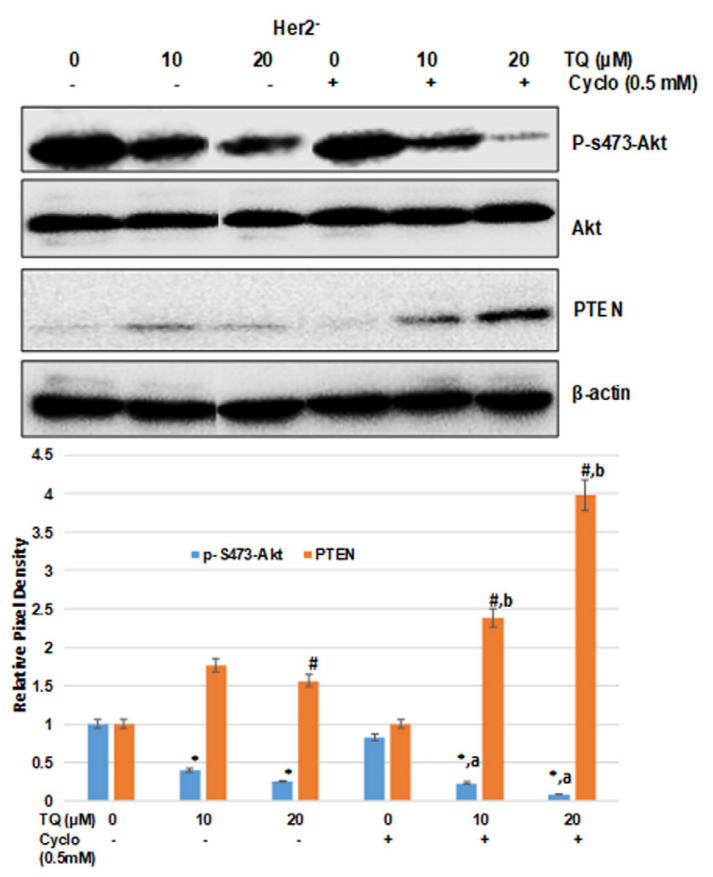

Figure 3. TQ Inhibited Akt Phosphorylation and Increased the Expression of Its Inhibitor PTEN in Dose-Dependent Manner in (A) HER2+ breast cancer cells (B) Her2- breast cancer cells. 1 X 106 cell in $100 \mathrm{~mm}$ plates were treated with TQ $(10,20 \mu \mathrm{M})$ with or without cyclo $(0.5 \mathrm{mM})$ for $48 \mathrm{~h}$. The total protein was isolated and Western blot analysis was performed as described in materials and methods with antibodies specific for phosphorylated-S473-Akt, Akt and PTEN. Data shown are the results of three independent experiments, and were represented as the relative densities of protein bands normalized to $\beta$-actin. *Significant difference compared with vehicle control $(0.0 \mu \mathrm{M})$ for $\mathrm{p}-5473$ Akt $(p<0.001)$, a Significant difference compared with cyclo alone $(0.5 \mathrm{mM})$ for $\mathrm{p}-5473-\mathrm{Akt}(\mathrm{p}<0.001)$ in Her2+ cells. \#Significant difference compared with vehicle control $(0.0 \mu \mathrm{M})$ for PTEN $(\mathrm{p}<0.001)$, \#Significant difference compared with cyclo alone $(0.5 \mathrm{mM})$ for PTEN $(\mathrm{p}<0.001)$ in Her2- cells.

A

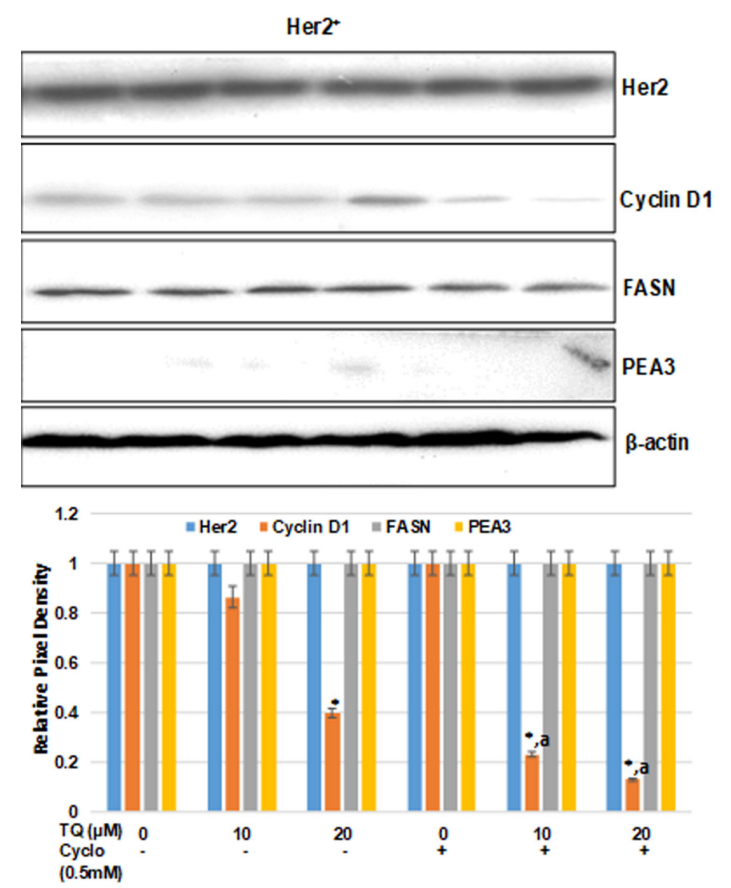

B

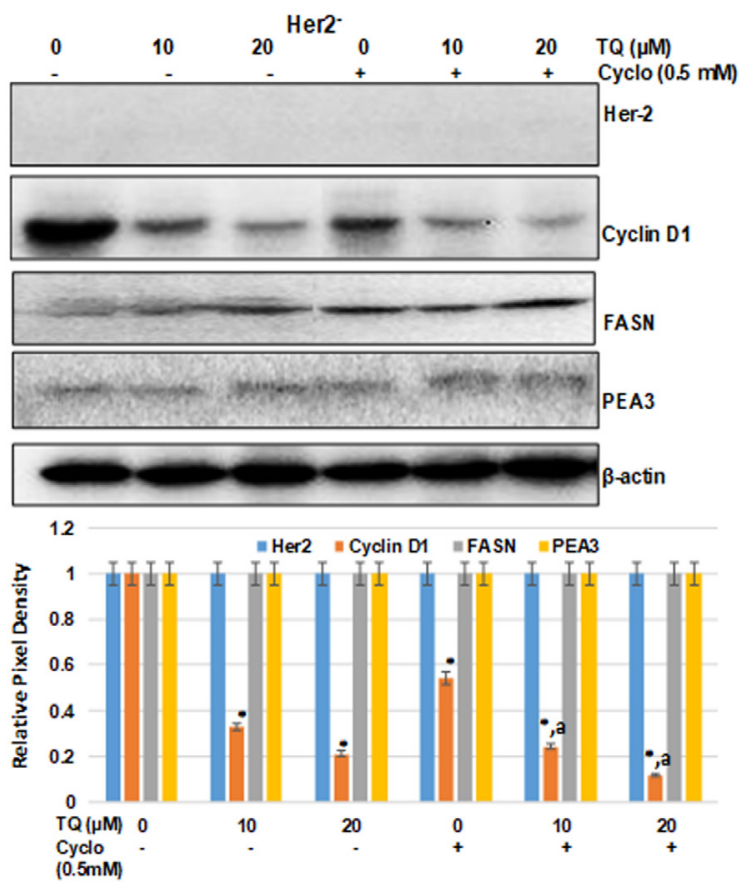

Figure 4. TQ Downregulated the Cyclin-D1 Independent of FASN and Her2 (a) HER2+ Breast Cancer Cells (b) Her2breast cancer cells. 1 X 106 cell in $100 \mathrm{~mm}$ plates were treated with TQ $(10,20 \mu \mathrm{M})$ with or without cyclo $(0.5 \mathrm{mM})$ for $48 \mathrm{~h}$. The total protein was isolated, and western blot analysis was performed as described in materials and methods section with antibodies specific for p185Her2, Cyclin-D1, FASN, PEA3. Equal loading was confirmed by re-probing the membrane with $\beta$-actin. Data shown are the results of three independent experiments, and were represented as the relative densities of bands normalized to $\beta$-actin. *Significant difference compared with vehicle control $(0 \mu \mathrm{M})$ for Cyclin D $(\mathrm{p}<0.001)$, a Significant difference compared with cyclo $(0.5 \mathrm{mM})$ for Cyclin $\mathrm{D}(\mathrm{p}<0.001)$. 
A
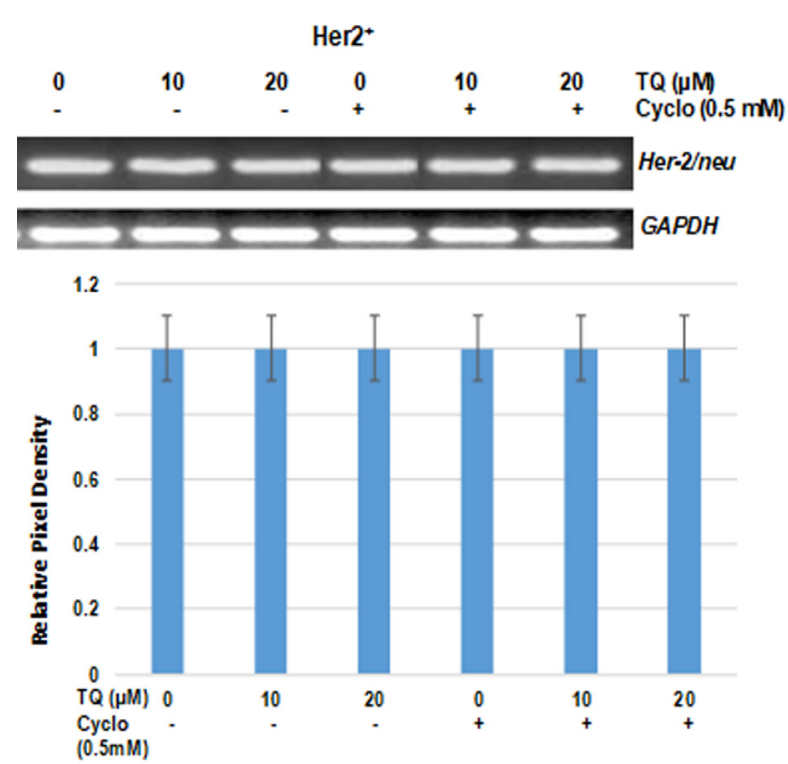

B

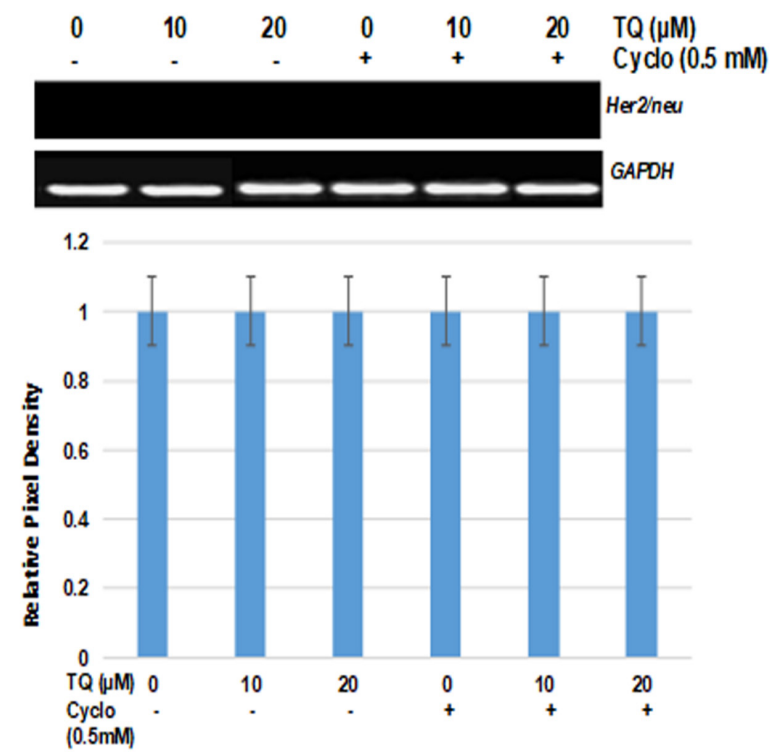

Figure 5. TQ Had Vo Effect on Her2 Promoter Activity Through Binding of Its Transcriptional Regulator PEA3. 1 X 106 cell in $100 \mathrm{~mm}$ plates were treated with TQ $(10,20 \mu \mathrm{M})$ with or without cyclo $(0.5 \mathrm{mM})$ for $48 \mathrm{~h}$. RT-PCR analyses for Her2 and GADPH transcripts and expression were performed as described in materials and methods section. Data shown are the results of three independent experiments and were represented as the relative densities of bands normalized to GAPDH.

combination through FASN mediated signaling . To gain additional insight and confirm the findings, we examined the expression of Her2 regulators PEA3 and Cyclin D1. It is indicated that her-2 promoter activity is suppressed by Ets transcription factor PEA3, leading to inhibition of Her2 mediated carcinogenesis (Oliver et al., 1998; Wang et al., 2000). In this study, no change was observed in PEA3 expression in all the treated groups, but significantly decreased expression of cyclin D1 was recorded in both TQ-cyclo combinations (Figure $4 \mathrm{a}$ and b). Additionally, we also tried to examine any transcriptional changes in the expression of Her2 gene other than PEA3. As shown in Figure $4 \mathrm{a}$ and $\mathrm{b}$, no change was observed in any of the treated groups in comparison vehicle controls in both of the cells. According to findings of this study, it seems that TQ either alone or in combination with cyclo has no role in Her-FASN mediated signaling.

\section{Discussion}

Given the toxic effect of anticancer conventional drugs at recommended doses, concomitant use of dietary constituents with less amount of synthetic drugs has been suggested. In the last two decades, many naturally occurring substances have been reported to prevent the occurrence of carcinogenesis at various stages (Pitchaiah et al., 2017; Lefranc et al., 2017). In this regard, TQ has shown its huge potential to protect against experimental carcinogenesis and molecular mechanism in various cancer cell lines and different model animals of cancer (Rajput et al., 2013; Salim et al., 2013; Dastjerdi et al., 2016; Khan et al., 2017).

As evident from several studies, the increased activity of FASN in various human cancers, including breast cancer is associated with the progression of the malignant phenotype (Alo et al., 2001; Wang et al., 2004; Fiorentino et al., 2008; Migita et al., 2009; Gonzalez-Guerrico et al., 2016). Therefore, pharmacological inhibitors of FASN have attracted great attention as the suppression of FASN evidently inhibits the cell proliferation and escalates the rate of apoptosis all together in human and mouse melanoma cells (Liu et al., 2010; Benjamin et al., 2015). The potential of nutraceuticals such as green tea polyphenol epigallocatechin-3-gallate (EGCG) and other flavonoids against breast cancer by downregulating the FASN activity has been suggested by previous studies (Tian et al., 2006; Pan et al., 2007; Puig et al., 2008; Khan et al., 2014).

In the present study, our results clearly demonstrated the potential of TQ to amplify the effect of cyclo at a very low dose $(0.5 \mathrm{mM})$. We also identified no role for FASN and Her2 mediated signaling in TQ alone or TQ in combination with cyclo. In the current study, we found that TQ inhibited the cell proliferation independent of any changes in the expression of Her2 either at transcriptional or translation level (Figure 4,5). As depicted in Figure 4a and $b$, no change was either observed in PEA3, which specifically reverses the in vitro transformed phenotype of Her2+ breast cancer cells by reducing Her2 oncogene promoter activity (Xing et al., 2000).

The current findings suggested that TQ can alter the cell cycle progression and induce cell death independent of FASN mediated signaling. Future studies are suggested to investigate the exact molecular mechanism in the inhibition of cancer cell proliferation for TQ alone and TQ in combination with cyclo. It also paves us the way to prepare the liposome-based various formulations of TQ-cyclo for effective delivery with increasing doses.

The present study limited to only two types of cells, which need to include several types of breast 
cancer cells to understand the possible mechanisms of TQ-cyclo combination in detail for further investigations. In terms of clinical perspective, the present study clearly showed that TQ may broadly augment the effect of cyclophosphamide in breast cancer cases irrespective of Her2+ or Her-.

\section{Funding Statement}

This study was supported in part by the Deanship Scientific Research, Grant \# 3155, Qassim University, Saudi Arabia.

\section{Statement conflict of Interest}

The authors declare no competing financial interests.

\section{Acknowledgements}

We acknowledge all the staff members of College of Applied Medical Sciences for their co-operation to conduct this research.

\section{References}

Alo PL, Visca P, Botti C, et al (2001). Immunohistochemical expression of human erythrocyte glucose transporter and fatty acid synthase in infiltrating breast carcinomas and adjacent typical/atypical hyperplastic or normal breast tissue. Am J Clin Pathol, 116, 129-34.

Arafa ESA, Zhu Q, Shah ZI, et al (2011). Thymoquinone up-regulates PTEN expression and induces apoptosis in doxorubicin-resistant human breast cancer cells. Mutat Res, 706, 28-35.

Benjamin DI, Li DS, Lowe W, et al (2015). Diacylglycerol metabolism and signaling is a driving force underlying FASN inhibitor sensitivity in cancer cells. ACS Chem Biol, 10, 1616-23.

Bhatt AP, Jacobs SR, Freemerman AJ, et al (2012). Dysregulation of fatty acid synthesis and glycolysis in non-Hodgkin lymphoma. PNAS, 109, 11818-23.

Cai Y, Wang J, Zhang L, et al (2014). Expressions of fatty acid synthase and HER2 are correlated with poor prognosis of ovarian cancer. Medi Oncol, 32, 391.

Chan TO, Rittenhouse SE, Tsichlis PN (1999). AKT/PKB and other D3 phosphoinositide-regulated kinases: kinase activation by phosphoinositide-dependent phosphorylation. Annu Rev Biochem, 68, 965-1041.

Chou TC, Talalay P (1984). Quantitative analysis of dose-effect relationships: the combined effects of multiple drugs or enzyme inhibitors. Adv Enzyme Regul, 22, 27-55.

Dastjerdi MN, Mehdiabady EM, Iranpour FG, Bahramian H (2016). Effect of thymoquinone on P53 gene expression and consequence apoptosis in breast cancer cell line. Int $J$ Prev Med, 7, 66.

Dirican A, Atmaca H, Bozkurt E, et al (2015). Novel combination of docetaxel and thymoquinone induces synergistic cytotoxicity and apoptosis in DU-145 human prostate cancer cells by modulating PI3K-AKT pathway. Clin Transl Oncol, 17, 145-51.

Fiorentino M, Zadra G, Palescandolo E, et al (2008). Overexpression of fatty acid synthase is associated with palmitoylation of Wnt1 and cytoplasmic stabilization of $\beta$-catenin in prostate cancer. Lab Invest, 88, 1340-48.

Gonzalez-Guerrico I, Espinoza B Schroeder CH, et al (2016). Suppression of endogenous lipogenesis induces reversion of the malignant phenotype and normalized differentiation in breast cancer. Oncotarget, 7, 71151-68.

Harpole JL, Tucci M, Benghuzzi H (2015). Pathophysiological effects of thymoquinone and epigallocatechin-3-gallate on SK-OV-3 ovarian cancer like cell line. Biomed Sci Instrum, $\mathbf{5 1}, 31-9$.

Khan A, Aljarbou AN, Debasi YH, Faisal SM, Khan MA(2014). Resveratrol suppresses the proliferation of breast cancer cells by inhibiting fatty acid synthase signalling pathway. Cancer Epidemiol, 38, 765-72.

Khan MA, Aljarbou AN, Khan A, Younus H (2015). Liposomal thymoquinone effectively combats fluconazole-resistant Candida albicans in murine mode. Int J Biol Macromol, 20, 203-08.

Khan MA, Tania M, Fu S, Fu J (2017). Thymoquinone, as an anticancer molecule: from basic research to clinical investigation. Oncotarget, 8, 51907-919.

Kuhajda FP, Pizer ES, Li JN, et al (2000). Synthesis and antitumor activity of an inhibitor of fatty acid synthase. Proc Natl Acad Sci US A, 97, 3450-4.

Lefranc F, Tabanca N, Kiss R (2017). Assessing the anticancer effects associated with food products and/or nutraceuticals using in vitro and in vivo preclinical development-related pharmacological tests. Semin Cancer Biol, 46, 14-32.

Lei X, Lv X, Liu M, et al (2012). Thymoquinone inhibits growth and augments 5-fluorouracil-induced apoptosis in gastric cancer cells both in vitro and in vivo. Biochem Biophys Res Commun, 417, 864-8.

Liu H, Liu JY, Wu X, Zhang JT (2010). Biochemistry, molecular biology, and pharmacology of fatty acid synthase, an emerging therapeutic target and diagnosis/prognosis marker. Int J Biochem Mol Biol, 1, 69-89.

Migita T, Ruiz S, Fornari A, et al (2009). Fatty acid synthase: A metabolic enzyme and candidate oncogene in prostate cancer. J Natl Cancer Inst, 101, 519-32.

Norwood AA, Tucci M, Benghuzzi HA (2007). A Comparison of 5-fluorouracil and natural chemotherapeutic agents, EGCG and thymoquinone, delivered by sustained drug delivery on colon cancer cells. Biomed Sci Instrum, 43, 272-7.

Oliver FJ, de la Rubia G, Rolli V, et al (1998). Importance of poly(ADPribose) polymerase and its cleavage in apoptosis. Lesson from an uncleavable mutant. J Biol Chem, 273, 33533-9.

Pan MH, Lin CC, Lin JK, Chen WJ (2007). Tea polyphenol (-)-epigallocatechin 3-gallate suppresses heregulin-beta1induced fatty acid synthase expression in human breast cancer cells by inhibiting phosphatidylinositol 3-kinase/ Akt and mitogenactivated protein kinase cascade signaling. J Agric Food Chem, 55, 5030-7.

Pitchaiah G, Akula A, Chandi V (2017). Anticancer potential of nutraceutical formulations in MNU-induced mammary cancer in sprague dawley rats. Pharmacogn Mag, 13, 46-50.

Puig T, Vázquez-Martín A, Relat J, et al (2008). Fatty acid metabolism in breast cancer cells: differential inhibitory effects of epigallocatechin gallate (EGCG) and C75. Breast Cancer Res Treat, 109, 471-9.

Rajput S, Kumar BN, Dey KK, et al (2013). Molecular targeting of Akt by thymoquinone promotes $\mathrm{G}(1)$ arrest through translation inhibition of cyclin D1 and induces apoptosis in breast cancer cells. Life Sci, 93, 783-90.

Reddy L, Odhav B, Bhoola KD (2003). Natural products for cancer prevention: a global perspective. Pharmacol Ther, 99, 1-13.

Rysman E, Brusselmans K, Scheys K, et al (2010). De novo lipogenesis protects cancer cells from free radicals and chemotherapeutics by promoting membrane lipid saturation. Cancer Res, 70, 8117-26.

Salim LZ, Mohan S, Othman R, et al (2013). Thymoquinone 
induces mitochondria-mediated apoptosis in acute lymphoblastic leukaemia in vitro. Molecules, 18, 11219-40.

Su X, Ren Y, Yu N, Kong L, Kang J (2016). Thymoquinone inhibits inflammation, neoangiogenesis and vascular remodeling in asthma mice. Int Immunopharmacol, 38, 70-80.

Tian WX (2006). Inhibition of fatty acid synthase by polyphenols. Curr Med Chem, 13, 967-77.

Ventura R, Mordec K, Waszczuk J, et al (2015). Inhibition of de novo palmitate synthesis by fatty acid synthase induces apoptosis in tumor cells by remodeling cell membranes, inhibiting signaling pathways, and reprogramming gene expression. eBioMedicine, 2, 808-24.

Wang SC, Hung MC (2000). Transcriptional targeting of the HER2/neu oncogene. Drugs Today (Barc), 36, 835-43.

Wang YY, Kuhajda FP, Li J, et al (2004). Fatty acid synthase as a tumor marker: its extracellular expression in human breast cancer. J Exp Ther Oncol, 4, 101-10.

Williams S, Tucci MA, Benghuzzi HA (2014). The effect of combination treatments of epigallocatechin-3-gallate, thymoquinone, and 5-Fluorouracil on fadu nasopharyngeal carcinoma cells. Biomed Sci Instrum, 50, 361-6.

Xing X, Wang SC, Xia W, et al (2000). The ets protein PEA3 suppresses HER-2/neu overexpression and inhibits tumorigenesis. Nat Med, 6, 189-95.

Yi T, Cho SG, Yi Z, et al (2008). Thymoquinone inhibits tumor angiogenesis and tumor growth through suppressing AKT and extracellular signal-regulated kinase signaling pathways. Mol Cancer Ther, 7, 1789-96.

Younus H (2018). Action of thymoquinone. In 'Molecular and Therapeutic actions of Thymoquinone', Eds Younus H. Springer Nature, Singapore, pp 1-85.

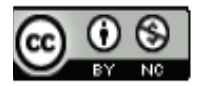

This work is licensed under a Creative Commons AttributionNon Commercial 4.0 International License. 